
\title{
$\begin{array}{ll}\text { Research Square } & \text { Preprints are preliminary reports that have not undergone peer review. } \\ \text { They should not be considered conclusive, used to inform clinical practice, } \\ \text { or referenced by the media as validated information. }\end{array}$
}

\section{Delineating Patterns of Sexualized Substance use and its Association with Sexual and Mental Health Outcomes Among Young Gay, Bisexual and Queer Men in Singapore: A Latent Class Analysis}

\author{
Rayner Kay Jin Tan ( $\square$ rayner.tan@u.nus.edu ) \\ National University of Singapore https://orcid.org/0000-0002-9188-3368 \\ Caitlin Alsandria O'Hara \\ National University Singapore Yong Loo Lin School of Medicine \\ Wee Ling Koh \\ National University Singapore Saw Swee Hock School of Public Health \\ Daniel Le \\ Action for AIDS Singapore \\ Avin Tan \\ Action for AIDS Singapore \\ Adrian Tyler \\ Action for AIDS Singapore \\ Calvin Tan \\ Action for AIDS Singapore \\ Chronos Kwok \\ Action for AIDS Singapore \\ Sumita Banerjee \\ Action for AIDS Singapore \\ Mee Lian Wong \\ National University Singapore Saw Swee Hock School of Public Health
}

Research article

Keywords: Chemsex, alcohol, poppers, MSM, Singapore

Posted Date: November 24th, 2020

DOI: https://doi.org/10.21203/rs.3.rs-113068/v1

License: (c) (1) This work is licensed under a Creative Commons Attribution 4.0 International License. Read Full License 


\section{Abstract}

Background: Young gay, bisexual, and other men who have sex with men (YMSM) are vulnerable to the risks associated with sexualized substance use. This is a novel study in Singapore that aims to classify patterns of sexualized substance use among YMSM, and investigate its association with sexual and mental health outcomes.

Methods: In this cross-sectional study among 570 YMSM aged 18 to 25 years old, latent class analysis (LCA) conducted to identify classes with similar patterns of sexualized substance use, across which measures of inconsistent condom use, recent STI diagnoses, past suicide ideation and depression severity were compared.

Results: LCA revealed three classes of YMSM based on types of substances ever used in sexualized contexts, which we labelled as 'substance-naïve', 'substance-novice', and 'chemsex'. Substance-naïve participants $(n=404)$ had only ever used alcohol, while substance-novice participants ( $n=143)$ were primarily amyl nitrite users with a small proportion who reported using chemsex-related drugs. Chemsex partiipants $(n=23)$ comprised individuals who had mostly used such drugs. Those in the chemsex group were more likely to report recent unprotected anal sex with casual partners, depression severity and a history of suicide ideation.

Conclusions: Findings of this study highlight how the use of varying substances in sexualized contexts may be classified and characterized by different sexual and mental health outcomes. Health promotion efforts should be differentiated accordingly to address the risks associated with sexualized substance use among YMSM.

\section{Background}

A total of approximately 37.9 million people were living with HIV as of 2017 (1). Gay, bisexual, and other men who have sex with men (GBMSM) constitute a key population that continues to be disproportionately affected by HIV on a global scale (2). Within communities of GBMSM, young gay, bisexual, and other men who have sex with men (YMSM) experience a greater burden of HIV and other sexually transmitted infections (STI) risk compared to their older counterparts, which may be attributed to a higher incidence of risky sexual behaviors, the lack of help-seeking behaviors, and sexualized substance use $(3,4)$.

Past studies have shown that the prevalence of drug use is higher among GBMSM, compared to the general heterosexual male population, and is often used in sexualized contexts (5-7). YMSM are also especially vulnerable to substance use disorders and the risks associated with them (8-10). Sexualized substance use has also been referred to by other terms such as 'chill fun', 'chemsex', 'party and play' and 'wired sex', which vary by country setting, and typically denote the use of substances such as mephedrone, amyl nitrites (poppers), gamma-hydroxybutyrate/gamma-butyrolactone (GHB/GBL), crystal methamphetamine (meth), as well as drugs usually prescribed for erectile dysfunction (ED) before or during sexual activity (11-13). Chemsex has been found to be positively associated with incidence of STI, behaviors associated with HIV and other STI risk acquisition, as well as poorer mental health outcomes (14, 15).

Apart from the use of typically illicit substances that characterize chemsex, heavy alcohol use has been established to be common among GBMSM, especially in developed country settings $(6,16,17)$. Past studies have also found that individuals who identify with any sexual minority status, including GBMSM, had initiated alcohol use at a younger age, compared to their heterosexual counterparts $(18,19)$. An early onset of alcohol initiation among GBMSM has been found to be associated with a greater number of lifetime sexual partners, elevated levels of depressive symptoms, and alcohol abuse later in life (20). Heavy alcohol use among GBMSM, and in particular the use of alcohol during or after sex, has also been found to be associated with behaviors associated with HIV acquisition risk, such as unprotected anal intercourse (21-23); however, these findings have been inconsistent due to methodological differences in measuring alcohol use and the lack of experimental study designs (24).

Past studies employing latent class analysis have found that substance use patterns may not be homogenous among GBMSM, and these classes are characterized by a range of substance use-related behaviors, from GBMSM who do not use substances in sexualized contexts, to those who engage in polydrug use during sex. These studies also find that these classes may be associated with varying sexual risk behaviors $(14,25)$. Similarly, the present study will conduct latent class analysis on data from the baseline analysis of the Pink Carpet Y Cohort Study (PCYCS), Singapore's first prospective cohort study among YMSM, to explore classes of sexualized substance use and its association with other sexual and mental health outcomes. This study is noteworthy as it is novel in the present setting, and allows us to better understand the risk factors that may be associated with substance use initiation among YMSM.

\section{Methods}

\section{Country setting}

GBMSM are disproportionately represented in prevalent cases of HIV in Singapore. As of 2019, a total of 8,295 incident HIV infections among Singapore residents have been notified to the Singapore ministry of health $(\mathrm{MOH})$. In 2011, yearly incident cases of HIV transmitted through male 'homosexual or bisexual' modes exceeded that of 'heterosexual' modes for the first time, and that trend has persisted since (26). Recent studies have found that a majority of Singapore residents hold negative perceptions of, and attitudes towards lesbian, gay, bisexual, and transgender (LGBT) individuals. Specifically, most perceived same-sex relationships as being wrong, and are also not in favor of the repeal of Section 377A, the law that criminalizes sexual relations between men $(27,28)$. Past studies have also established the negative impact and trickle-down effects that such stigma has on HIV prevention efforts among GBMSM in Singapore (29-31). 


\section{Participants and recruitment}

The PCYCS is a prospective cohort study exploring the syndemic risks associated with HIV and other sexually transmitted infections (STI) acquisition among YMSM in Singapore. This study was a partnership between Action for AIDS Singapore (AFA), one of Singapore's longest-running community-based organizations serving the health of GBMSM, and the National University of Singapore (NUS). To be eligible for this cohort, participants had to be HIV-negative or unsure of their HIV status, between the ages of 18 to 25 years old, Singapore citizens or permanent residents, and identify as gay, bisexual, or queer men at the point of recruitment, which spanned across May to September 2019. Participants were asked to self-report these attributes. Assuming a population of 210,000 GBMSM in Singapore (32), we targeted recruitment of at least 384 participants to achieve a $95 \%$ confidence level and $5 \%$ margin of error. However, 600 participants were targeted for recruitment to account for potential attrition at each follow-up for this cohort study.

Participants were invited to participate in this study through a recruitment flyer that was disseminated through both online (e.g. social media) and offline (e.g. at the organization's office or outreach activities) channels by a network of community-based organizations in Singapore who are engaged in health advocacy-related activities for GBMSM. Participants who were interested in participating and were eligible for the study signed up through an enrolment link with their self-reported alias, contact details, date of birth, gender, HIV status, sexual orientation, and their residence status. An AFA staff member subsequently verified the eligibility of participants who had signed up prior to sending them a unique identifier, and a link for the baseline survey.

It was imperative for the team to ensure that participants' identities their data would remain confidential, as drug use and sexual relations between men are criminalized in Singapore. To do so, the researchers ensured that no staff member from AFA or NUS had full access to either the enrolment details held by AFA which contained aliases and contact details of participants, and the baseline survey results held by NUS. Both sets of data were only linked by the unique identifier which participants entered at the beginning of the survey. Upon completion of the survey, a NUS staff member provided AFA with the unique identifiers who had completed the baseline survey, and an SGD20.00 (approximately USD15.00) cash reimbursement was given to the participant. A total of 570 participants were recruited at the baseline of the cohort; the response rate could not be established as it was not possible to ascertain the total number of eligible participants that the recruitment flyers had reached. Participants could also refer their friends to participate in the survey and be reimbursed SGD5.00 (approximately USD3.75) for each eligible individual successfully referred and who had completed the baseline survey; a total of 171 (30.0\%) of participants were recruited through referrals.

\section{Ethics declaration}

Ethics approval was obtained from the institutional review board at the National University of Singapore (NUS-IRB Reference Code S-19-007) prior to data collection.

\section{Variable measures}

The survey collected sociodemographic information from respondents, including age (in years), ethnicity (Chinese vs non-Chinese), gender (cisgender vs noncisgender), sexual orientation (gay vs non-gay), and monthly household income (SGD5000 and above vs below SGD5000; SGD5000 is approximately USD3668.94). As the YMSM in our sample included respondents who were still schooling, educational attainment and gross monthly personal income were omitted as variables, though they were collected in the baseline survey. Household income was thus collected and utilized as a proxy variable for socioeconomic status among participants.

Participants were asked if they had ever used a series of substances in sexual contexts, including alcohol, poppers, meth, GHB/GBL as well as other ED medication or drugs (e.g. Viagra, Cialis, 'black ants'). For sexual health outcomes, participants were asked about their patterns of unprotected anal sex, as well as STI diagnoses in the last six months. Unprotected anal sex with casual partners in the last six months was coded as a binary variable (yes vs no), and was derived from a series of questions that solicited frequency of self-reported condom use through a five-point Likert scale from 1 to 5 , with 1 being that they did not use condoms and 5 being that they had always used condoms; this question was repeated for permutations of oral and anal sex with regular, casual, and sex worker partners in the last six months. Participants who had not used condoms all the time with casual and sex worker partners in the last six months were coded as 'yes' under this variable. Participants who also reported being tested positive for either gonorrhoea, syphilis, chlamydia, genital herpes, genital warts or hepatitis $\mathrm{C}$ were assigned as having been diagnosed with an STI in the past six months through a binary (yes vs no) variable.

For mental health outcomes, both depression severity and past suicide ideation were measured. Depression severity, which was measured through the wellestablished, nine-item patient health questionnaire-9 (PHQ-9) validated by Kroenke and colleagues $(33,34)$. Participants were asked "over the last 2 weeks, how often have you been bothered by any of the following problems?" to a total of nine statements, to which they could respond to four possible answers on a Likert scale; 1 being not at all and 4 being nearly every day. Depression severity was measured as an index that was the sum score of all nine items, with a minimum score of 0 and a maximum score of 27 . Cronbach's alpha of the scale was reported as 0.92 . Participants were also asked about their suicide-related behaviors, including if they had ever contemplated suicide by responding to three possible answers: yes, no, or prefer not to say.

\section{Statistical analysis}

Statistical analysis was carried out using the statistical software STATA version 15 (Stata Corp, College Station, TX, USA). We employed descriptive statistics to identify trends in sample characteristics. Latent class analysis was performed with STATA's gsem function to delineate classes of drug use in sexualized contexts. The chosen variables included a history of using alcohol, poppers, meth, GHB/GBL as well as other ED medication or drugs (e.g. Viagra, Cialis, 'black ants') in sexualized contexts. A latent class model was employed, whereby the conditional item probabilities for each class and class probabilities were

Page 3/12 
estimated through maximum likelihood procedures. A posteriori probabilities were calculated using the predict post-estimation command. In order to determine the number of clusters, models with consecutively increasing were estimated and compared using both Akaike and Bayesian information criteria (AIC and BIC), but BIC was favored given its reliance on both the log-likelihood and the adjusted sample size (35). Given that the three-class model had the lowest AIC and BIC values, it was thus reported in this study. A summary of goodness-of-fit statistics are provided in Supplementary Table S1. Entropy, which provides a measure of how well individuals fit into each class, was also taken into account to determine the fit of the model. Following identification of latent classes, we sought to determine the association between varying classes with outcome variables of unprotected anal sex, STI diagnoses, depression severity and past suicide ideation while adjusting for key sociodemographic covariates. We employed multivariable Poisson regression models with robust sandwich variances to compute the crude prevalence ratio (PR) and adjusted prevalence ratio (aPR) estimating these outcome variables. Statistical significance was set at $\mathrm{p}<0.05$. Analysis for this study was not pre-registered and the results reported here should be considered exploratory.

\section{Results}

\section{Sociodemographic attributes and description of analytic sample}

Table 1

Description of analytic sample $(n=570)$

\begin{tabular}{|c|c|c|}
\hline Variables & $\mathrm{n} /$ Mean & $\% / S D$ \\
\hline Age & 21.9 & 2.17 \\
\hline Chinese ethnicity (Ref=Non-Chinese) & 478 & $83.9 \%$ \\
\hline Cisgender male (Ref=Transgender, genderqueer, or others) & 525 & $92.1 \%$ \\
\hline Gay (Ref=Bisexual, queer, or others) & 408 & $71.6 \%$ \\
\hline Monthly household income $\geq$ SGD5000 (Ref <SGD5000) & 203 & $35.6 \%$ \\
\hline \multicolumn{3}{|l|}{ Ever had sexualized substance use with } \\
\hline Alcohol & 190 & $33.3 \%$ \\
\hline Amyl nitrites (Poppers) & 161 & $28.3 \%$ \\
\hline Crystal methamphetamine (Meth) & 27 & $4.7 \%$ \\
\hline Gamma-hydroxybutyrate/gamma-butyrolactone (GHB/GBL) & 27 & $4.7 \%$ \\
\hline Erectile dysfunction drugs (ED) & 26 & $4.6 \%$ \\
\hline Ever contemplated suicide & 308 & $54.0 \%$ \\
\hline Unprotected anal sex with casual partners in the last 6 months & 96 & $16.8 \%$ \\
\hline Tested positive for an STI in the last 6 months & 39 & $6.8 \%$ \\
\hline Depression severity (PHQ-9) & 7.9 & 6.79 \\
\hline
\end{tabular}

A total of 570 participants were recruited in this study. Table 1 summarizes the sociodemographic attributes and overall description of the analytic sample. In terms of their sociodemographic attributes, the mean age of the sample was 21.9 years $(S D=2.17) .83 .9 \%$ of the participants identified as Chinese ( $n=478$ ), $92.1 \%$ identified as cisgender male $(n=525), 71.6 \%$ identified as gay $(n=408)$, and $35.6 \%$ reported a monthly household income of SGD5000 and above $(n=203)$. A total of 33.5\% ( $n=189), 28.0 \%(n=158), 4.6 \%(n=26), 4.6 \%(n=26)$, and 4.6\% $(n=26)$ reported ever using alcohol, poppers, meth, GHB/GBL, and ED medication or drugs in sexual contexts, respectively.

With regard to the outcome variables of the study, participants reported a mean score of $7.9(\mathrm{SD}=6.79)$ on depression severity, while most participants had ever contemplated suicide $(n=308,54.1 \%)$. A total of $16.8 \%$ of participants also reported unprotected anal sex with casual partners in the last six months $(n=96)$, while $6.7 \%(n=38)$ reported testing positive for an STI in the past six months.

\section{Patterns of sexualized substance use}


Table 2

Description of analytic sample by predicted substance-using classes $(n=570)$

\begin{tabular}{|c|c|c|c|c|c|c|c|}
\hline \multirow[t]{2}{*}{ Variables } & \multicolumn{2}{|c|}{$\begin{array}{l}\text { Substance-Naïve } \\
(n=404)\end{array}$} & \multicolumn{2}{|c|}{$\begin{array}{l}\text { Substance-Novice } \\
(n=143)\end{array}$} & \multicolumn{2}{|c|}{ Chemsex $(n=23)$} & \multirow{2}{*}{$\begin{array}{l}\text { Fisher's Exact } \\
\text { Test } \\
\text { p-value }\end{array}$} \\
\hline & n/Mean & $\% / S D$ & n/Mean & $\% / S D$ & n/Mean & $\% / S D$ & \\
\hline Age & 21.7 & 2.18 & 22.4 & 2.11 & 22.3 & 1.77 & 0.001 \\
\hline Chinese ethnicity (Ref=Non-Chinese) & 336 & $83.2 \%$ & 124 & $86.7 \%$ & 18 & $78.3 \%$ & 0.436 \\
\hline Cisgender male (Ref=Transgender, genderqueer, or others) & 365 & $90.4 \%$ & 139 & $97.2 \%$ & 21 & $91.3 \%$ & 0.018 \\
\hline Gay (Ref=Bisexual, queer, or others) & 268 & $66.3 \%$ & 122 & $85.3 \%$ & 18 & $78.3 \%$ & $<0.001$ \\
\hline Monthly household income $\geq$ SGD5000 (Ref <SGD5000) & 131 & $32.4 \%$ & 65 & $45.5 \%$ & 7 & $30.4 \%$ & 0.019 \\
\hline \multicolumn{8}{|l|}{ Ever had sexualized substance use with } \\
\hline Alcohol & 96 & $76.2 \%$ & 81 & $56.6 \%$ & 13 & $56.5 \%$ & $<0.001$ \\
\hline Amyl nitrites (Poppers) & 0 & $0.0 \%$ & 139 & $97.2 \%$ & 22 & $95.7 \%$ & $<0.001$ \\
\hline Crystal methamphetamine (Meth) & 0 & $0.0 \%$ & 5 & $3.5 \%$ & 22 & $95.7 \%$ & $<0.001$ \\
\hline $\begin{array}{l}\text { Gamma-Hydroxybutyrate/Gamma-Butyrolactone } \\
\text { (GHB/GBL) }\end{array}$ & 0 & $0.0 \%$ & 5 & $3.5 \%$ & 22 & $95.7 \%$ & $<0.001$ \\
\hline Erectile dysfunction drugs (ED) & 0 & $0.0 \%$ & 9 & $6.3 \%$ & 17 & $73.9 \%$ & $<0.001$ \\
\hline Ever contemplated suicide & 207 & $51.2 \%$ & 82 & $57.3 \%$ & 19 & $82.6 \%$ & 0.007 \\
\hline $\begin{array}{l}\text { Unprotected anal sex with casual partners in the last } 6 \\
\text { months }\end{array}$ & 51 & $12.6 \%$ & 36 & $25.2 \%$ & 9 & $39.1 \%$ & $<0.001$ \\
\hline Tested positive for an STI in the last 6 months & 22 & $5.5 \%$ & 15 & $10.5 \%$ & 2 & $8.7 \%$ & 0.083 \\
\hline Depression severity (PHQ-9) & 7.9 & 6.69 & 7.4 & 6.60 & 11.4 & 8.87 & 0.030 \\
\hline
\end{tabular}

LCA revealed three classes (AIC=1743.14; BIC=1808.33), which we labelled post hoc as 'Substance-naïve', 'Substance-novice', and 'Chemsex'. Participants in the substance-naïve $(n=403)$ class reported only ever using alcohol $(n=96,76.2 \%)$, and never using any other substances during sex. Participants in the substance-novice class ( $n=143$ ) had mostly ever used poppers during sex ( $n=139,97.2 \%)$, with some reporting ever using meth ( $n=5,3.9 \%)$, GHB/GBL ( $n=5$, $3.9 \%)$, and erectile dysfunction drugs $(n=9,6.3 \%)$ during sex, over and above those who reported ever using alcohol during sex ( $n=81,56.6 \%)$. A similar proportion of participants in the chemsex class $(n=23)$ reported ever using alcohol $(n=13,56.5 \%)$ and poppers during sex ( $n=22,95.7 \%)$, but a large proportion reported ever using meth $(n=22,95.7 \%), G H B / G B L(n=22,95.7 \%)$, and erectile dysfunction drugs $(n=17,73.9 \%)$ during sex. Table 2 describes the analytic sample by substance using classes, while Figure 1 summarizes the proportion of individuals who reported ever using varying substances by substance using classes.

\section{Association between substance use class membership and sexual health outcomes}


Table 3

Multivariable Poisson regression for sexual health outcomes and its association with substance using classes

\begin{tabular}{|c|c|c|c|c|c|c|c|c|}
\hline & \multicolumn{4}{|c|}{$\begin{array}{l}\text { Unprotected anal sex with casual partners in the last six } \\
\text { months }(n=96)\end{array}$} & \multicolumn{4}{|c|}{$\begin{array}{l}\text { STI diagnoses in the last six months } \\
(n=39)\end{array}$} \\
\hline & PR & $95 \% \mathrm{Cl}$ & aPR & $95 \% \mathrm{Cl}$ & PR & $95 \% \mathrm{Cl}$ & aPR & $95 \% \mathrm{Cl}$ \\
\hline Age & 0.94 & $(0.87,1.02)$ & 0.91 & $(0.84,0.99)$ & 0.95 & $\begin{array}{l}(0.83, \\
1.08)\end{array}$ & 0.92 & $\begin{array}{l}(0.80 \\
1.06)\end{array}$ \\
\hline Chinese ethnicity (Ref=Non-Chinese) & 0.83 & $(0.53,1.32)$ & 0.85 & $(0.53,1.36)$ & 0.75 & $\begin{array}{l}(0.35 \\
1.57)\end{array}$ & 0.72 & $\begin{array}{l}(0.35, \\
1.51)\end{array}$ \\
\hline $\begin{array}{l}\text { Cisgender male (Ref=Transgender, genderqueer, } \\
\text { or others) }\end{array}$ & 0.83 & $(0.45,1.53)$ & 0.77 & $(0.43,1.37)$ & 1.59 & $\begin{array}{l}(0.39 \\
6.37)\end{array}$ & 1.42 & $\begin{array}{l}(0.36 \\
5.63)\end{array}$ \\
\hline Gay (Ref=Bisexual, queer, or others) & 1.13 & $(0.74,1.71)$ & 1.04 & $(0.67,1.60)$ & 1.32 & $\begin{array}{l}(0.64, \\
2.73)\end{array}$ & 1.19 & $\begin{array}{l}(0.57 \\
2.46)\end{array}$ \\
\hline $\begin{array}{l}\text { Monthly household income } \geq \text { SGD } 5000 \text { (Ref } \\
<\text { <GD 5000) }\end{array}$ & 0.82 & $(0.55,1.22)$ & 0.79 & $(0.52,1.19)$ & 0.90 & $\begin{array}{l}(0.47 \\
1.72)\end{array}$ & 0.88 & $\begin{array}{l}(0.46, \\
1.67)\end{array}$ \\
\hline \multicolumn{9}{|l|}{ Classes } \\
\hline Substance-naïve & ref & ref & ref & ref & ref & ref & ref & ref \\
\hline Substance-novice & 1.99 & $(1.36,2.92)$ & 2.24 & $(1.51,3.33)$ & 1.93 & $\begin{array}{l}(1.03 \\
3.61)\end{array}$ & 2.01 & $\begin{array}{l}(1.05 \\
3.85)\end{array}$ \\
\hline Chemsex & 3.10 & $(1.75,5.49)$ & 3.28 & $(1.85,5.79)$ & 1.60 & $\begin{array}{l}(0.40 \\
6.39)\end{array}$ & 1.64 & $\begin{array}{l}(0.42 \\
6.38)\end{array}$ \\
\hline \multicolumn{9}{|l|}{ Notes } \\
\hline \multicolumn{9}{|c|}{ Abbreviations: Cl, Confidence Interval; PR, Prevalence Ratio; aPR, Adjusted Prevalence Ratio } \\
\hline \multicolumn{9}{|c|}{ Statistically significant $(p<0.05)$ are highlighted in bold font } \\
\hline
\end{tabular}

At the bivariate level, participants who were in the substance-novice (PR=1.99, 95\% Cl [1.36, 2.92]) and chemsex $(\mathrm{PR}=3.10,95 \% \mathrm{Cl}[1.75,5.49])$ classes were more likely than substance-naïve participants to have reported engaging in unprotected anal sex with a casual partner in the last six months. Participants who were in the substance-novice class were also more likely that those in the substance-naïve class to have reported a diagnosis for any STI in the last six months (PR=1.93, 95\% Cl $[1.03,3.61])$. At the multivariable level, analyses revealed that an increasing age was negatively associated with $(\mathrm{aPR}=0.91,95 \% \mathrm{Cl}$ $[0.84,0.99])$, while participants who were in the substance-novice $(\mathrm{aPR}=2.24,95 \% \mathrm{Cl}[1.51,3.33])$ and chemsex $(\mathrm{aPR}=3.28,95 \% \mathrm{Cl}[1.85,5.79])$ classes were more likely than substance-naïve participants to have reported engaging in unprotected anal sex with a casual partner in the last six months. Participants who were in the substance-novice class were also more likely that those in the substance-naïve class to have reported a diagnosis for any STI in the last six months $(\mathrm{aPR}=2.01,95 \% \mathrm{Cl}[1.05,3.85])$.

\section{Association between substance use class membership and mental health outcomes}


Table 4

Multivariable poisson regression for mental health outcomes and its association with substance using classes

\begin{tabular}{|c|c|c|c|c|c|c|c|c|c|c|c|}
\hline & \multicolumn{5}{|c|}{ Ever contemplated suicide $(n=308)$} & \multicolumn{6}{|c|}{ Depression severity } \\
\hline & PR & $95 \% \mathrm{Cl}$ & aPR & & $95 \% \mathrm{Cl}$ & $\beta$ & & $95 \% \mathrm{Cl}$ & $a \beta$ & & $95 \% \mathrm{Cl}$ \\
\hline Age & 0.96 & \multicolumn{2}{|c|}{$(0.93,1.00)$} & 0.96 & \multicolumn{2}{|c|}{$(0.93,0.99)$} & -0.41 & \multicolumn{2}{|c|}{$(-0.66,-0.15)$} & -0.39 & $\begin{array}{l}(-0.65 \\
-0.14)\end{array}$ \\
\hline Chinese ethnicity (Ref=Non-Chinese) & 0.87 & \multicolumn{2}{|c|}{$(0.72,1.04)$} & 0.87 & \multicolumn{2}{|l|}{$(0.72,1.04)$} & -1.92 & \multicolumn{2}{|c|}{$(-3.43,-0.40)$} & -1.86 & $\begin{array}{l}(-3.37 \\
-0.34)^{\prime}\end{array}$ \\
\hline $\begin{array}{l}\text { Cisgender male (Ref=Transgender, } \\
\text { genderqueer, or others) }\end{array}$ & 0.89 & \multicolumn{2}{|c|}{$(0.69,1.15)$} & 0.88 & \multicolumn{2}{|c|}{$(0.69,1.14)$} & -2.48 & \multicolumn{2}{|c|}{$(-4.55,-0.42)$} & -2.13 & $\begin{array}{l}(-4.22 \\
-0.04)\end{array}$ \\
\hline Gay (Ref=Bisexual, queer, or others) & 1.04 & \multicolumn{2}{|c|}{$(0.88,1.24)$} & 1.06 & \multicolumn{2}{|l|}{$(0.89,1.26)$} & -0.55 & \multicolumn{2}{|c|}{$(-1.7,-0.69)$} & 0.04 & $\begin{array}{l}(-1.22, \\
1.31)\end{array}$ \\
\hline $\begin{array}{l}\text { Monthly household income } \geq \text { SGD5000 (Ref } \\
<\text { SGD5000) }\end{array}$ & 1.00 & \multicolumn{2}{|c|}{$(0.86,1.18)$} & 1.02 & \multicolumn{2}{|l|}{$(0.87,1.20)$} & 0.33 & \multicolumn{2}{|c|}{$(-0.83,1.50)$} & 0.69 & $\begin{array}{l}(-0.48, \\
1.86)\end{array}$ \\
\hline \multicolumn{12}{|l|}{ Classes } \\
\hline Substance-naïve & ref & ref & \multicolumn{2}{|l|}{ ref } & ref & \multicolumn{2}{|l|}{ ref } & Ref & \multicolumn{2}{|l|}{ ref } & Ref \\
\hline Substance-novice & 1.12 & $(0.94,1.33)$ & \multicolumn{2}{|l|}{1.16} & $(0.97,1.38)$ & \multicolumn{2}{|l|}{-0.52} & $(-1.81,0.78)$ & \multicolumn{2}{|l|}{-0.11} & $\begin{array}{l}(-1.43 \\
1.21)\end{array}$ \\
\hline Chemsex & 1.61 & $(1.31,1.99)$ & 1.64 & & $(1.33,2.03)$ & 3.51 & & $(0.66,6.36)$ & 3.69 & & $\begin{array}{l}(0.87 \\
6.51)\end{array}$ \\
\hline \multicolumn{12}{|l|}{ Notes } \\
\hline
\end{tabular}

At the bivariate level, increasing age was positively associated with ever contemplating suicide (PR=0.96, 95\% $\mathrm{Cl}[0.93,1.00])$. Participants who were in the chemsex class ( $\mathrm{PR}=1.61,95 \% \mathrm{Cl}[1.31,1.99])$ were more likely than substance-naïve participants to have reported ever contemplating suicide. Increasing age (Beta $=-0.41,95 \% \mathrm{Cl}[-0.66,-0.15])$, being of Chinese ethnicity (Beta=-1.92, 95\% $\mathrm{Cl}[-3.43,-0.40])$, and identifying as a cisgender male (Beta $=-2.48,95 \% \mathrm{Cl}[-4.55$, -0.42]) were negatively associated with depression severity. Participants who were in the chemsex class were also more likely that those in the substancenaïve class to have reported higher scores for depression severity (Beta=3.51, 95\% $\mathrm{Cl}[0.66,6.36])$. All factors that were statistically significant at the bivariate level remain significant at the multivariable level. Increasing age was positively associated with ever contemplating suicide (PR=0.96, 95\% Cl [0.93, 0.99]). Participants who were in the chemsex class ( $\mathrm{PR}=1.64,95 \% \mathrm{Cl}[1.33,2.03])$ were more likely than substance-naïve participants to have reported ever contemplating suicide. Increasing age (Beta $=-0.39,95 \% \mathrm{Cl}[-0.65,-0.14])$, being of Chinese ethnicity (Beta $=-1.86,95 \% \mathrm{Cl}[-3.37,-0.34])$, and identifying as a cisgender male (Beta=-2.13,95\% $\mathrm{Cl}[-4.22,-0.04]$ ) were negatively associated with depression severity. Participants who were in the chemsex class were also more likely that those in the substance-naïve class to have reported higher scores for depression severity $(\mathrm{Beta}=3.69,95 \% \mathrm{Cl}[0.87,6.51])$.

\section{Discussion}

This study sought to identify classes of YMSM based on the substances that they had ever used in sexualized contexts. We explored the sociodemographic and substance use patterns across each of the different classes, and how these classes differed based on their associations with a variety of sexual and mental health outcomes, specifically recent unprotected anal sex with casual partners and STI diagnoses, as well as depression severity and ever contemplating suicide. This study is noteworthy in that, to our knowledge, no prior study has sought to delineate classes of substance use specifically in younger samples of MSM, which allows us to better understand the risk factors that may be associated with substance use initiation. Furthermore, no other study had ever sought to investigate such patterns of substance use among GBMSM in Singapore.

Results of latent class analysis revealed three classes of YMSM based on the substances that they had ever used in sexualized contexts, which we labelled post hoc as 'substance-naïve', 'substance novice', and 'chemsex. Those in the substance-naïve group had only ever used alcohol, while the substance-novice group were primarily poppers users with a small proportion who reported using drugs typically associated with chemsex, including meth, GHB/GBL, as well as erectile dysfunction drugs $(13,36)$. The chemsex group comprised individuals who had mostly used such drugs. This finding aligns with that of other studies, which identified classes of GBMSM characterized by those who were negligible or non-users of recreational substances excluding alcohol, those who were 'soft' drug users, and those who were 'hard' drug or polydrug users (25). Several studies have also found find greater nuances in such patterns of use, separating those who are polydrug users without meth or mephedrone, and those who do $(14,37)$.

Controlling for potential confounders, we found that being in the substance-novice or chemsex classes were associated with poorer sexual and mental health outcomes, compared to those who were in the substance-naïve class. Given that those in the chemsex class reported both historical and recent indicators of poorer mental health, we believe that this may underpin certain mechanisms that lead to both sexual risk and substance use risk-related behaviors. This corroborates the findings of other studies $(38,39)$. As we are not able to establish causation due to the study design, an alternative explanation would be that substance use itself may be a factor that may cause poorer mental health, and disinhibition associated with sexual risk-related behaviors, which corroborate the findings of other studies as well (40). These two may mechanisms may also be working in tandem to exacerbate poorer sexual and mental health 
outcomes in the chemsex class, compared to the substance-naïve class of YMSM. We remain mindful that we cannot draw a direct association between

substance use and some of these outcomes as the time frame assessed for both differ.

Our study has several strengths. As it was conducted among self-identified HIV-negative YMSM aged 18 to 25 years old, we may be identifying certain risk factors and substance use patterns that may place them at risk of HIV and other STI acquisition. We may also draw conclusions around factors that may be associated with substance use initiation without stronger confounds of age, as GBMSM are more likely to be exposed to various substances throughout their life course due to its cumulative availability via sexual and social networks (41).

We are mindful of several limitations in our study. As only HIV-negative YMSM were recruited in this study, we may have missed out on HIV-positive YMSM whom may exhibit higher levels of substance use, which would be consistent with the findings of the other studies $(42,43)$. Furthermore, as drug use carries with it severe penalties in Singapore, participants may not be entirely honest with their answers around drug use, which may have led to an underreporting of substance use in the present sample. This form of non-differential misclassification would have biased our results towards the null, when in fact the associations between substance use and the outcomes of interest would have been stronger.

We have several recommendations for health promotion and policy interventions. Overall, such health promotion efforts and interventions should acknowledge that substance use-related support needs among YMSM and GBMSM may be heterogenous, and would require a combination of upstream interventions that promote literacy around the risks associated with substance use, and downstream ones that mitigate such risks or promote the well-being of those who require long-term support. Findings of this study indicate that efforts for early intervention and education for YMSM should focus on addressing suicide and depression, which may be associated with future HIV and other STI acquisition risk and other risks associated with substance use.

\section{Abbreviations}

GBMSM: Gay, Bisexual and other Men who have Sex with Men

YMSM: Young Men who have Sex with Men

STI: Sexually Transmitted Infections

GHB/GBL: Gamma-Hydroxybutyrate/Gamma-Butyrolactone

AFA: Action for AIDS Singapore

NUS: National University of Singapore

SGD: Singapore Dollars

GHB/GBL: Gamma Hydroxybutyrate and Gamma-Butyrolactone

C: Coefficient

PR: Prevalence Ratio

\section{Declarations}

\section{Ethics approval and consent to participate:}

Ethics approval was provided by the National University of Singapore Institutional Review Board (Reference Code S-19-007). Participants provided written informed consent to participate.

\section{Consent for publication:}

Prior to data collection, participants were given a copy of the participant information sheet and subsequently provided written informed consent by clicking on a link.

\section{Availability of data and materials:}

The datasets used and/or analysed during the current study are available from the corresponding author on reasonable request.

\section{Competing interests:}

The authors declare that they have no competing interests

Funding: 
This research is supported by the Singapore Ministry of Health's National Medical Research Council under the Seed Funding Programme by Singapore Population Health Improvement Centre (NMRC/CG/C026/2017_NUHS). The funder had no role in the design of the study and collection, analysis, and interpretation of data and in writing the manuscript.

\section{Authors' contributions:}

RKJT, DL, SB and WML conceptualized the study; WML provided supervision for the study; RKJT and WML acquired the funding for the study; CAO, WLK and RKJT conducted formal analyses; RKJT, DL, AT, ATy, CT, CK and SB conducted the investigation and curated the data associated with the study; CAO, WLK and RKJT wrote the original draft; All co-authors have reviewed and approved of the manuscript prior to submission.

\section{Acknowledgements:}

The study team would like to thank all the participants who took part in the study. We would like to extend our sincerest thanks to Action for AIDS Singapore and the Pink Carpet $Y$ Team for their collaboration on this project. We would like to extend our sincerest gratitude to all community-based organizations who have helped us in the recruitment of participants. This research is supported by the Singapore Ministry of Health's National Medical Research Council under the Seed Funding Programme by Singapore Population Health Improvement Centre (NMRC/CG/C026/2017_NUHS).

\section{References}

1. UNAIDS. Global HIV \& AIDS statistics - 2019 fact sheet 2019 [cited 2019 July 24]. Available from: https://www.unaids.org/en/resources/fact-sheet.

2. Beyrer C, Baral SD, van Griensven F, Goodreau SM, Chariyalertsak S, Wirtz AL, et al. Global epidemiology of HIV infection in men who have sex with men. Lancet. 2012;380(9839):367-77.

3. Qi J, Zhang D, Fu X, Li C, Meng S, Dai M, et al. High Risks of HIV Transmission for Men Who Have Sex with Men - A Comparison of Risk Factors of HIV Infection among MSM Associated with Recruitment Channels in 15 Cities of China. PLOS ONE. 2015;10(4):e0121267.

4. Singh S, Song R, Johnson AS, McCray E, Hall HI. HIV Incidence, Prevalence, and Undiagnosed Infections in U.S. Men Who Have Sex With MenEstimated HIV Incidence, HIV Prevalence, and Undiagnosed HIV Infections. Annals of Internal Medicine. 2018;168(10):685-94.

5. Bourne A. Drug use among men who have sex with men. Implications for harm reduction. In: Stoicescu C, editor. Global State of Health Reduction 2012. London: Harm Reduction International; 2012. p. 147-55.

6. McCabe SE, Hughes TL, Bostwick WB, West BT, Boyd CJ. Sexual orientation, substance use behaviors and substance dependence in the United States. Addiction (Abingdon, England). 2009;104(8):1333-45.

7. Hunter LJ, Dargan PI, Benzie A, White JA, Wood DM. Recreational drug use in men who have sex with men (MSM) attending UK sexual health services is significantly higher than in non-MSM. Postgraduate Medical Journal. 2014;90(1061):133-8.

8. Freeman P, Walker BC, Harris DR, Garofalo R, Willard N, Ellen JM, et al. Methamphetamine use and risk for HIV among young men who have sex with men in 8 US cities. Arch Pediatr Adolesc Med. 2011;165(8):736-40.

9. Clatts MC, Goldsamt LA, Yi H. Club Drug Use Among Young Men Who Have Sex with Men in NYC: A Preliminary Epidemiological Profile. Substance Use \& Misuse. 2005;40(9-10):1317-30.

10. Kecojevic A, Silva K, Sell RL, Lankenau SE. Prescription Drug Misuse and Sexual Risk Behaviors Among Young Men Who have Sex with Men (YMSM) in Philadelphia. AIDS and behavior. 2015;19(5):847-56.

11. Bourne A, Reid D, Hickson F, Torres-Rueda S, Weatherburn P. Illicit drug use in sexual settings ('chemsex') and HIV/STI transmission risk behaviour among gay men in South London: findings from a qualitative study. Sexually Transmitted Infections. 2015;91(8):564-8.

12. Race K. 'Party and Play': Online hook-up devices and the emergence of PNP practices among gay men. Sexualities. 2015;18(3):253-75.

13. Tan RKJ, Wong CM, Chen MIC, Chan YY, Bin Ibrahim MA, Lim OZ, et al. Chemsex among gay, bisexual, and other men who have sex with men in Singapore and the challenges ahead: A qualitative study. International Journal of Drug Policy. 2018;61:31-7.

14. Achterbergh RCA, de Vries HJC, Boyd A, Davidovich U, Drückler S, Hoornenborg E, et al. Identification and characterization of latent classes based on drug use among men who have sex with men at risk of sexually transmitted infections in Amsterdam, the Netherlands. Addiction. 2020;115(1):121-33.

15. Bourne A, Weatherburn P. Substance use among men who have sex with men: patterns, motivations, impacts and intervention development need. Sexually Transmitted Infections. 2017;93(5):342-6.

16. Stall R, Paul JP, Greenwood G, Pollack LM, Bein E, Crosby GM, et al. Alcohol use, drug use and alcohol-related problems among men who have sex with men: the Urban Men's Health Study. 2001;96(11):1589-601.

17. Lea T, Ryan D, Prestage G, Zablotska I, Mao L, de Wit J, et al. Alcohol use among a community-based sample of gay men: Correlates of high-risk use and implications for service provision. 2015;34(4):349-57.

18. Corliss HL, Rosario M, Wypij D, Fisher LB, Austin SB. Sexual Orientation Disparities in Longitudinal Alcohol Use Patterns Among Adolescents: Findings From the Growing Up Today Study. Arch Pediatr Adolesc Med. 2008;162(11):1071-8.

19. Garofalo R, Wolf RC, Kessel S, Palfrey J, DuRant RH. The Association Between Health Risk Behaviors and Sexual Orientation Among a School-based Sample of Adolescents. 1998;101(5):895-902.

20. Grosso AL, Downing MJ, Thomann M, Chiasson MA, Schrimshaw EW, Hirshfield S. Age of Onset of Alcohol Consumption and Subsequent Negative Health Outcomes in Gay and Bisexual Men Who Have Sex With Men. Journal of Homosexuality. 2019;66(11):1609-25.

Page $9 / 12$ 
21. Washington TA, Patel SN, Meyer-Adams N. Drinking Patterns and HIV Risk Behaviors Among Black and Latino Men Who Have Sex Within Los Angeles County. 2017;11(4):834-44.

22. Li J, McDaid LM. Alcohol and drug use during unprotected anal intercourse among gay and bisexual men in Scotland: what are the implications for HIV prevention? 2014;90(2):125-32.

23. Bolton R, Vincke J, Mak R, Dennehy E. Alcohol and risky sex: In search of an elusive connection. Medical Anthropology. 1992;14(2-4):323-63.

24. Woolf S, Maisto S. Alcohol Use and Risk of HIV infection among Men Who Have Sex with Men. AIDS and Behavior. 2008;13(4):757-82.

25. Lim SH, Cheung DH, Guadamuz TE, Wei C, Koe S, Altice FL. Latent class analysis of substance use among men who have sex with men in Malaysia: Findings from the Asian Internet MSM Sex Survey. Drug and Alcohol Dependence. 2015;151:31-7.

26. Ministry of Health Singapore. Update on the HIV/AIDS Situation in Singapore 2019 (June 2020) 2020 [Available from: https://www.moh.gov.sg/resourcesstatistics/infectious-disease-statistics/hiv-stats/update-on-the-hiv-aids-situation-in-singapore-2019-(june-

2020)\#: :text=2019\%20(JUNE\%202020)-,UPDATE\%200N\%20THE\%20HIV\%2FAIDS\%20SITUATION\%20IN\%20SINGAPORE\%202019\%20(JUNE,whom\%202

27. Chua L. J. SD, Tan R. K. J., Jie, K. W. Decriminalisation of Same-sex Relations and Social Attitudes: An Empirical Study of Singapore. Hong Kong Law Journal. 2017;47(3):793-824.

28. Mathews M, Lim L, Selvarajan S. Religion, morality and conservatism in Singapore. Singapore: Institute of Policy Studies; 2019.

29. Tan RKJ, Kaur N, Kumar PA, Tay E, Leong A, Chen MIC, et al. Clinics as spaces of costly disclosure: HIV/STI testing and anticipated stigma among gay, bisexual and queer men. Culture, Health \& Sexuality. 2019:1-14.

30. Tan RKJ, Teo AKJ, Kaur N, Harrison-Quintana J, Chen MI-C, Wong CS. Extent and selectivity of sexual orientation disclosure and its association with HIV and other STI testing patterns among gay, bisexual, and other men who have sex with men. Sexually transmitted infections. 2019.

31. Tan RKJ. Internalized Homophobia, HIV Knowledge, and HIV/AIDS Personal Responsibility Beliefs: Correlates of HIV/AIDS Discrimination among MSM in the Context of Institutionalized Stigma. Journal of Homosexuality. 2018:1-22.

32. Teo AKJ, Prem K, Chen MIC, Roellin A, Wong ML, La HH, et al. Estimating the size of key populations for HIV in Singapore using the network scale-up method. 2019:sextrans-2018-053747.

33. Kroenke K, Spitzer RL, Williams JB. The PHQ-9: validity of a brief depression severity measure. J Gen Intern Med. 2001;16(9):606-13.

34. Spitzer RL, Kroenke K, Williams JBW, Group atPHQPCS. Validation and Utility of a Self-report Version of PRIME-MDThe PHQ Primary Care Study. JAMA. 1999;282(18):1737-44.

35. Nylund KL, Asparouhov T, Muthén BO. Deciding on the Number of Classes in Latent Class Analysis and Growth Mixture Modeling: A Monte Carlo Simulation Study. Structural Equation Modeling: A Multidisciplinary Journal. 2007;14(4):535-69.

36. Bourne A, Reid D, Hickson F, Torres Rueda S, Weatherburn P. The Chemsex study: drug use in sexual settings among gay and bisexual men in Lambeth, Southwark and Lewisham. 2014.

37. McCarty-Caplan D, Jantz I, Swartz J. MSM and Drug Use: A Latent Class Analysis of Drug Use and Related Sexual Risk Behaviors. AIDS and Behavior. 2014;18(7):1339-51.

38. Meyer IH. Prejudice, social stress, and mental health in lesbian, gay, and bisexual populations: conceptual issues and research evidence. Psychological bulletin. 2003;129(5):674-97.

39. Sewell J, Cambiano V, Miltz A, Speakman A, Lampe FC, Phillips A, et al. Changes in recreational drug use, drug use associated with chemsex, and HIVrelated behaviours, among HIV-negative men who have sex with men in London and Brighton, 2013-2016. Sexually Transmitted Infections. 2018;94(7):494.

40. Javanbakht M, Shoptaw S, Ragsdale A, Brookmeyer R, Bolan R, Gorbach PM. Depressive symptoms and substance use: Changes overtime among a cohort of HIV-positive and HIV-negative MSM. Drug and Alcohol Dependence. 2020;207:107770.

41. Holloway IW. Substance use homophily among geosocial networking application using gay, bisexual, and other men who have sex with men. Archives of sexual behavior. 2015;44(7):1799-811.

42. Semple SJ, Strathdee SA, Zians J, Patterson TL. Factors associated with experiences of stigma in a sample of HIV-positive, methamphetamine-using men who have sex with men. Drug and alcohol dependence. 2012;125(1-2):154-9.

43. Lewis LA, Ross MW. The Gay Dance Party Culture in Sydney. Journal of Homosexuality. 1995;29(1):41-70.

\section{Figures}


Substance-Naïve (n=404)

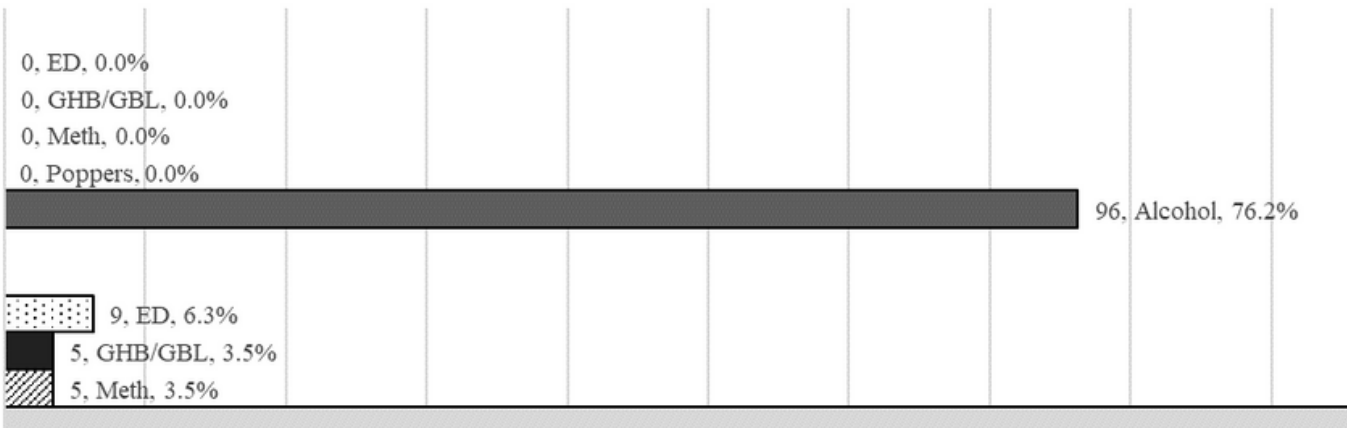

Substance-Novice $(n=143)$

5. GHB/GBL, $3.5 \%$

IIA 5eth, 3.5\%

139, Poppers, $97.2 \%$

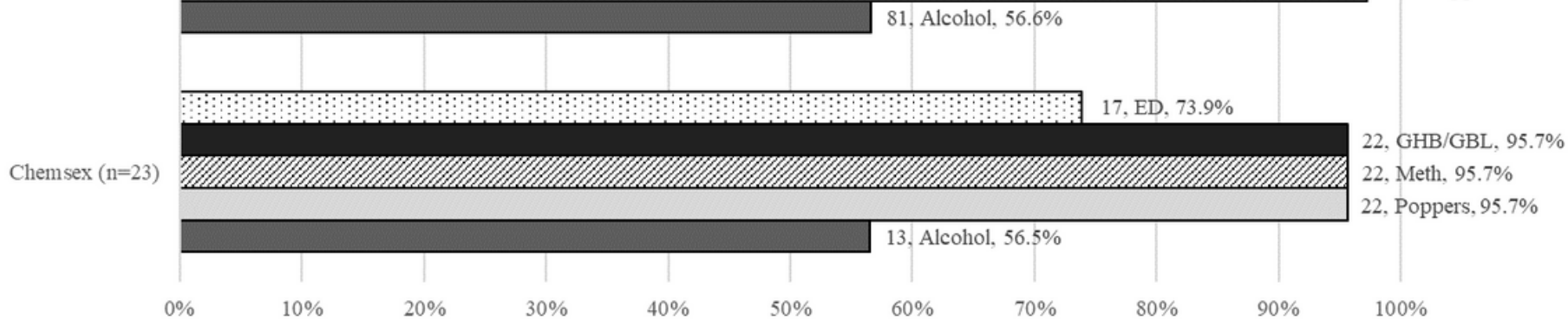

\section{Figure 1}

Proportion of types of substances used by predicted classes ( $n=570)$ Abbreviation: ED, Erectile Dysfunction Drugs; GHB/GBL, GammaHydroxybutyrate/Gamma-Butyrolactone; Meth, Crystal Methamphetamine

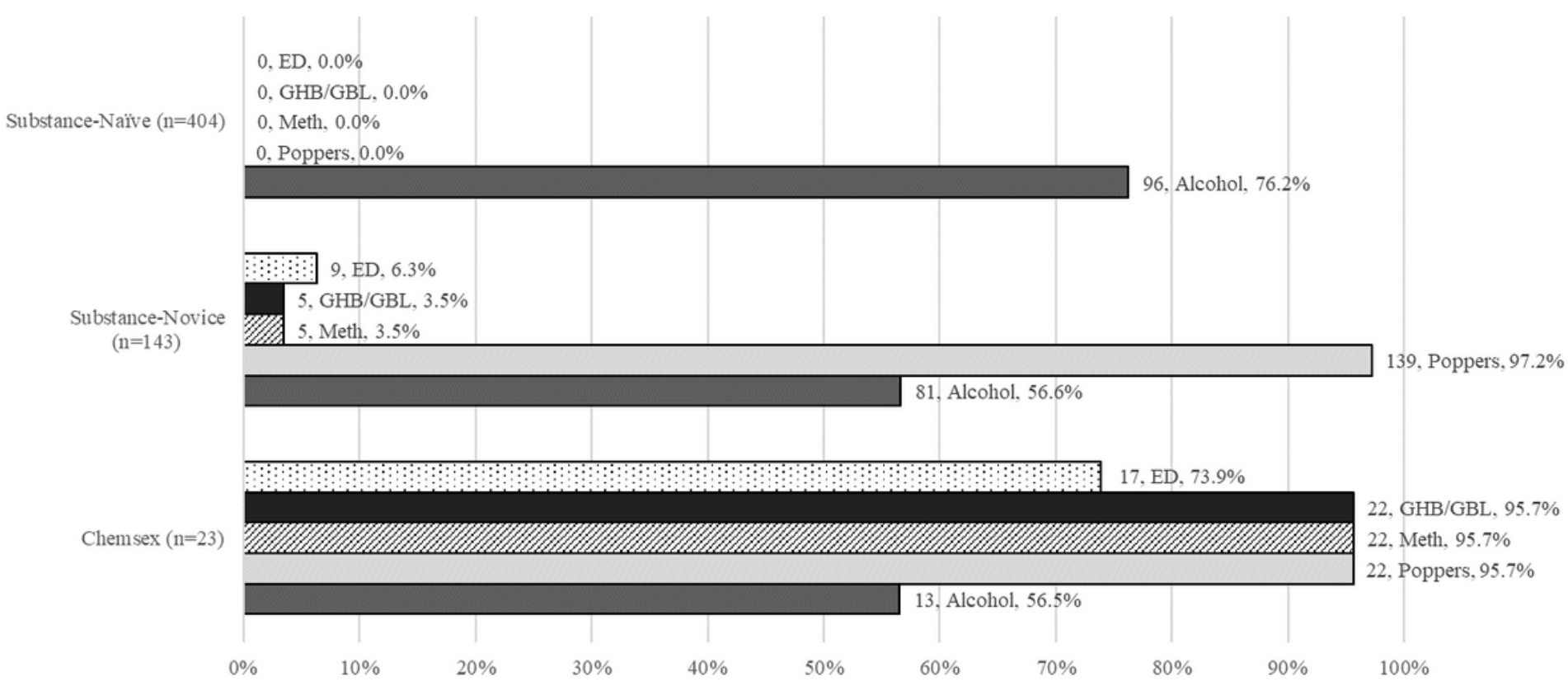

\section{Figure 1}

Proportion of types of substances used by predicted classes $(n=570)$ Abbreviation: ED, Erectile Dysfunction Drugs; GHB/GBL, GammaHydroxybutyrate/Gamma-Butyrolactone; Meth, Crystal Methamphetamine

\section{Supplementary Files}

This is a list of supplementary files associated with this preprint. Click to download.

- Tables1.docx 
- Tables1.docx

- STROBEchecklistv4combined.doc

- STROBEchecklistv4combined.doc

Page 12/12 